\title{
AS DESIGUALDADES DIANTE DA EDUCAÇÃO E SEUS EFEITOS SOCIAIS
}

\author{
INTRODUÇÃO
}

Maria Ligia de Oliveira Barbosa*

Um conjunto de questões relativas à escolaridade, educação e desigualdades socais contemporâneas têm sido objeto de particular atenção dos cientistas brasileiros e inspiraram os trabalhos ${ }^{1}$ que integram o presente dossiê. O conjunto dessas preocupações nos últimos anos se expressam nas seguintes questões:

- Os dilemas associados à expansão da escolarização para diferentes grupos sociais, particularmente as variações em termos de classes, etnias e gêneros, e a polarização entre eqüidade e eficiência, que tradicionalmente estrutura as políticas sociais voltadas para o setor.

- As relações entre educação e trabalho nas novas condições de mercado e, particularmente, o valor dos diplomas na sociedade brasileira, focalizando

* Professor-Doutor da Universidade Federal do Rio de Janeiro. Largo de São Francisco, 1 - Centro - CEP: 20051-070 Rio de Janeiro, RJ - Brasil. Telefone: (021) 22248965. mligia@ifcs.ufrj.br

${ }^{1}$ Os artigos que integram esse dossiê resultam de uma revisão mais aprofundada dos trabalhos apresentados no Grupo de Trabalho Educação e Sociedade (ANPOCS, 2006). O reconhecimento dos participantes sobre a riqueza empírica dos trabalhos apresentados e a sua própria organização temática estimularam os autores a uma revisão com vistas à publicação desse dossiê. a hipervalorização do diploma de nível superior, constatada por toda uma tradição de estudos.

- A escolaridade e seus efeitos sobre as identidades, num contexto de intensificação acelerada das trocas internacionais, que promove modificações importantes nos recursos materiais e simbólicos necessários às formas de inserção social valorizadas pelos diferentes grupos sociais.

- As identidades coletivas, o espaço escolar e a “concorrência” de espaços alternativos de formação, concretizados nas iniciativas dos movimentos sociais, mas também nos meios de comunicação de massa.

- A evolução e as tendências de mudanças nas formas de organização dos sistemas de ensino: diversificação, descentralização e burocratização.

- A escola e os enfrentamentos políticos, ideológicos e (ou) religiosos, geralmente abordados por meio de antinomias, tais como as que opõem público e privado, religiosidades diferenciadas e perspectivas laicas, pedagogias tradicionais e dialógicas, culturas dominantes e culturas populares.

Os artigos que discutem essas temáticas fo- 
ram organizados em três blocos. No primeiro, temos estudos voltados para a compreensão das formas socialmente diferenciadas de entrada e vivência na escola. No bloco seguinte, apresentamse artigos que analisam, sob dois ângulos distintos, o valor atribuído à educação na sociedade brasileira. No terceiro e último bloco, apresentam-se três artigos que discutem evidências importantes de pesquisa empírica, numa área que coloca imensos desafios à pesquisa sociológica sobre educação: as diferentes formas institucionais pelas quais se realiza o trabalho educativo.

A partir dos três estudos incluídos nesse primeiro bloco, de autoria de Zaia Brandão (A produção das elites escolares: escolas, famílias e cultura), Graziela Perosa (Família e escola na socialização das meninas), e Wilson Almeida (Estudantes com desvantagens econômicas e educacionais e fruição da universidade), pode-se constatar a complexidade dos significados do processo de socialização escolar. Grupos sociais distintos apropriam-se de maneiras distintas dos recursos disponibilizados pelo sistema escolar, experimentando, nas trajetórias até certo ponto parecidas, sentidos, sensibilidades, significados, facilidades e dificuldades muito diferentes, cujas regularidades evidenciam as bases estamentais da socialização primária e o caráter socialmente distintivo das estratégias individuais.

O estudo de Zaia Brandão, realizado a partir de uma amostra de nove escolas cariocas consideradas de alto nível, que incluiu 850 alunos, 251 pais e 144 professores, mostra como a decantada qualidade das escolas de elite resultaria de uma combinação virtuosa das práticas educativas familiares e escolares. Do lado das famílias, encontrase um verdadeiro manual das características que incentivam o bom desempenho escolar, passando da permanência na mesma escola aos baixos índices de repetência dos estudantes, sem deixar de lado uma convivência familiar sólida e permeada de diálogo. Entre essas práticas virtuosas das famílias, destacam-se aquelas que favorecem e reforçam as estratégias de conversão dos diversos capitais que convergem para um acúmulo do capital cultural (bem) certificado: a valorização da leitura e da cultura letrada. Um ponto alto do texto é a apresentação de evidências que mostram que a presença de um determinado estilo de gestão escolar e de práticas docentes tem como efeito reforçar o já favorável conjunto de fatores educativos familiares dos alunos, fazendo com que a passagem por tais escolas agregue, efetivamente, valores mais elevados que os previstos, no caso de tais famílias. Com isso, não só dá-se relevo à problemática dos efeitos da instituição escolar como se evidencia a premência do aprofundamento das pesquisas sobre os professores e seus efeitos. Mas mostra-se, com clareza, que o conhecimento sobre as relações entre a posição social familiar e as trajetórias escolares ainda depende de pesquisa mais fina e detalhada, de forma a capturar as formas distintas de apropriação dos espaços escolares segundo as classes sociais.

Nessa mesma linha, o artigo de Graziela Perosa trata das trajetórias de mulheres egressas de colégios paulistanos de elite, resgatando os efeitos de reforço mútuo entre as perspectivas familiares e os diferentes estilos de condução da educação nos três estabelecimentos, o que resulta em formas particulares de incorporação dos estereótipos de gênero e de classe. Aqui, as diferenças de estilo referem-se às preferências familiares por escolas mais "modernas", mais "austeras", ou simplesmente “clássicas”. Também nesse estudo, são enfatizadas as características peculiares dos agentes educativos, no caso, religiosas e suas respectivas congregações, que têm impactos decisivos sobre o processo de construção das identidades das ex-alunas e, portanto, de um habitus específico que marca suas trajetórias. Em nível bastante detalhado, são mostradas as práticas cotidianas, os atos mais banais que, dentro da escola, estabelecem ou reforçam modos de agir e pensar comuns a essas meninas e que depois se transformam em padrões de ação dessas mulheres no mundo a elas destinado. Merece destaque a análise das estratégias de atração das famílias, utilizadas por cada congregação para buscar as alunas que teriam maiores afinidades com os padrões educativos desenvolvi- 
dos em cada instituição. Mais uma vez, a pesquisa aponta a força dos efeitos da instituição escolar, os quais constituem fatores fundamentais das estratégias familiares de reprodução ou elevação de sua posição social.

Finalmente, o artigo de Wilson Mesquita de Almeida, de certa maneira, inverte o foco: agora são os estudantes de camadas sociais menos privilegiadas que têm ingresso numa instituição de elite, e o problema das formas de apropriação e fruição do espaço escolar mostra-se de maneiras novas e complexas. O estudo procura focalizar as diferenças que caracterizam a permanência desses alunos na universidade e as dificuldades extremas por eles enfrentadas, que vão do desconhecimento sobre os princípios básicos de funcionamento da vida universitária e mesmo dos recursos e instrumentos que ela oferece, à necessidade de mudanças, inclusive pessoais, que possam assegurar um convívio minimamente humano nesse novo mundo. A leitura dos depoimentos desses alunos é uma evidência pungente da sociologia bourdieusiana, pois demonstra os mecanismos pelos quais, sutil mas firmemente, a instituição escolar constrói-se como espaço de privilégio. Ao mesmo tempo, esses depoimentos e a análise realizada chamam a atenção para o outro lado da obra do autor francês, segundo a qual, quando a instituição escolar cumpre suas tarefas propriamente escolares, ela consegue (ou, pelo menos, aproxima-se disso) oferecer a todos os seus alunos, independentemente de sua origem social, a possibilidade de usufruir adequadamente dos recursos sociais dos quais ela é a principal portadora. A experiência na USP cria (ou pode criar) algumas das condições necessárias à superação das barreiras da própria socialização primária que dificultam a fruição completa do ambiente universitário. Tudo isso sem deixar de lado o que o autor chama de "ethos do esforço (descomunal)" que permeia a visão que esses alunos têm do próprio sucesso. Mas, ao mesmo tempo, o texto destaca ainda os pontos em que a instituição poderia atuar no sentido de cumprir esse papel atribuído por Bourdieu. $\mathrm{Ou}$, como diriam as outras autoras, cujos textos compõem esta seção, no sentido de criar um ciclo virtuoso de combinação de características familiares e escolares, para se garantir um caráter mais democrático à passagem pela escola e aos resultados dessa passagem.

Os três textos representam vários dos avanços recentes da pesquisa sociológica em educação, particularmente no que diz respeito à compreensão mais profunda e adequada dos efeitos da instituição escolar, diferenciados socialmente. Ao mesmo tempo, eles apontam também para os problemas que vêm redesenhando a pauta dessa pesquisa, com destaque especial para a necessidade de se estudar a participação dos diversos agentes educativos, principalmente os professores. Eé com uma tentativa de análise, ainda preliminar, desse grupo profissional que se inicia a segunda sessão desse dossiê, cujo tema seria o valor da educação na sociedade brasileira contemporânea. Não se trata de discutir a economia da educação, mas de analisar o valor socialmente atribuído à educação no Brasil, sob dois ângulos específicos: as formas de organização das carreiras docentes no país, no caso do texto de Aparecida Néri de Souza, e a percepção e valorização atribuída aos diplomas escolares nos processos de contratação de executivos, no caso do artigo de Karla Régnier.

O artigo de Aparecida Néri, "Professores, trabalho e mercado", analisa as flutuações do mercado de trabalho entre 1992 e 2004, a partir de dados das PNADs e dos Censos Demográficos, ambos do IBGE. É interessante verificar a importante contribuição do setor de serviços educacionais para a elevação do nível de formalização do trabalho no período analisado. Nesse estudo exploratório, parte inicial de um projeto de pesquisa, descrevem-se as condições que podemos chamar de "demográficas" da categoria profissional docente, com destaque especial para os professores do ensino técnico. Essa demografia é um passo essencial para a caracterização da identidade profissional do grupo, um dos que mais cresceu na estrutura ocupacional brasileira. Mas o estudo vai além e detalha também dimensões sociais relevantes da identidade coletiva, no que tange ao 
ensino técnico: a presença feminina, marca importante da categoria no plano geral, não se confirma nessa área específica, e a escolarização dos professores se revela, ao mesmo tempo, o problema mais evidente e a proposta de solução mais complicada. Também são analisados fatores como idade, muitas vezes associada à experiência profissional, posição na ocupação, referente principalmente ao grau de formalização do trabalho docente, bastante elevado relativamente a outros tipos de trabalho, e à distinção entre setores público e privado. Quanto aos salários, há um dado interessante no estudo: apesar de considerados baixos pelos próprios docentes, seus salários são relativamente mais elevados que aqueles recebidos pelos demais trabalhadores. O conjunto de informações analisadas mostra especificidades importantes da categoria profissional e indica problemas de pesquisa relevantes, tanto no que diz respeito às condições ou possibilidades de instituição de uma identidade coletiva a partir de uma diversidade tão marcante de formação e níveis de escolaridade, quanto no que diz respeito à própria situação do grupo na hierarquia das profissões e ocupações, devido às peculiaridades da sua inserção no mercado.

No artigo de Karla Régnier, "O que conta como mérito no processo de pré-seleção de gerentes e executivos no Brasil", é discutido, numa outra dimensão, o valor da educação na sociedade brasileira. Analisando as transformações no significado atribuído à noção de mérito, a autora mostra como a educação superior é cada vez mais exigida, ao mesmo tempo em que, num contexto de expansão e diversificação de diplomas, ela se torna cada vez menos suficiente para a obtenção de um emprego de alto nível. Nesse quadro, a própria definição de mérito vai adquirindo dimensões inusitadas, como é o caso de novos critérios para seleção, como a experiência internacional ou vivência cultural diferenciada, ou ainda a realização de algum tipo de trabalho voluntário. Nesse quadro, coloca-se a questão do grau em que prevalece uma definição mais claramente associada às qualificações adquiridas, como educação, ou às características resultantes de herança familiar, como é o caso da experiência internacional. Tal tipo de questão mostra-se essencial quando se trata de analisar as possibilidades de democratização social via escolarização, característica definidora das sociedades meritocráticas. E o desafio que se coloca à pesquisa sociológica é o de compreender os jogos sociais, segundo os quais algumas qualificações passam a ser demandadas ou são descartadas, e como, nessas disputas, o valor da educação vai sendo alterado, aparentemente, na direção perversa, do ponto de vista democrático. Ou seja, é necessário explicar como a valorização da trajetória escolar passa a se associar necessariamente a outros elementos da vida familiar que acabam conferindo à escola uma dimensão de herança. Não será essa a mesma questão posta pelos textos da primeira sessão desse dossiê?

Para finalizar com mais desafios, também complexos, os estudos do último bloco tratam das formas diferenciadas e, por vezes, concorrentes, de atuação educativa. Trata-se de buscar caminhos para a análise das formas de constituição de espaços alternativos de formação, concretizados nas iniciativas dos movimentos sociais, em outros tipos de organização que buscam se afirmar no espaço educacional, ou ainda pela apropriação dos espaços tradicionais de educação por grupos antes excluídos deles. O primeiro texto desse bloco é o de Isaurora de Freitas, "Escola e ONG: educação formal e nãoformal de jovens da periferia de Fortaleza”. Seguese o de Denise Laranjeira, Ana Teixeira e Sylvain Bourdon, "Juventude, trabalho, educação: os jovens são o futuro do Brasil?".

No texto de Isaurora Freitas, encontramos um conjunto de ricos depoimentos sobre o trabalho de educação através da arte, realizado na periferia de Fortaleza. Esses dados são analisados de forma a verificar de que maneira a existência de formas educativas distintas, uma formal e outra não-formal, interagem e deixam marcas na trajetória de socialização dos jovens das camadas desfavorecidas, e como essas marcas se traduzem em tipos de inserção profissional de maior ou menor sucesso. São descritas as concepções sobre o processo educativo que orientam o trabalho da 
ONG estudada, e também são apresentadas as visões dos jovens que por aí passaram sobre o significado dessa experiência e da sua relação com a escola formal. A questão de pesquisa levantada por esse trabalho diz respeito tanto às possibilidades de inserção desses jovens no mercado, tendo como recurso esse tipo de educação, como às dissensões entre a socialização primária, recebida na família e a perspectiva construída no ambiente educativo, principalmente no caso da ONG. Assim, esse estudo faz retornar o debate que perpassa todo este dossiê sobre as apropriações distintas de saberes e práticas oferecidas pelas escolas e outros agentes educativos.

O tema da educação não-formal retorna no artigo de Denise Laranjeira, Ana Teixeira e Sylvain Bourdon e, novamente, o objeto de análise são jovens em situação desfavorecida,-- estigmatizados por sua posição social. Nesse caso, jovens que vivem na periferia de Salvador. O artigo procura analisar os efeitos da passagem por processos educativos alternativos sobre suas trajetórias sociais. São analisadas as representações de jovens que passaram por oficinas de teatro ou de eletricidade, promovidas por uma associação de moradores, tanto sobre a educação formal como sobre aquela que foi definida pelos autores como não-formal. Num quadro de presença rarefeita do Estado, a educação não-formal aparece como alternativa sedutora e como possibilidade de aprendizado prazeroso, contrastando marcadamente com a experiência na escola formal. Na verdade, o desafio parece ser colocado para as concepções tradicionais de ensino, que enfrentariam dificuldades para atrair jovens pobres e pouco educados. No entanto, para a pesquisa sociológica, seria importante capturar as dimensões sociais características dessas formas alternativas de educação, testar seus efeitos com maior regularidade e verificar, objetivamente, para além dos desejos bem intencionados e das ideologias, quais seriam as possibilidades efetivas que se desenham para uma educação inclusiva a partir dessas experiências.

Apesar da separação em três blocos, é fácil verificar que o tema que organiza o dossiê é único, expresso em perguntas, temáticas e esquemas explicativos diversos. Trata-se de compreender as disputas sociais travadas em torno de um recurso que se tornou decisivo nas sociedades modernas: a educação. Em cada um dos artigos são discutidas as formas pelas quais os diferentes grupos sociais procuram não só apropriar-se desse recurso, mas, principalmente, dar à educação o significado ou o sentido que lhes parece mais correto, mais legítimo, mais adequado. Em alguns deles, analisam-se as regras de funcionamento do sistema escolar; em outros, estudam-se as regras de validação e valorização social dos produtores e dos produtos desse mesmo sistema. Ou seja, através desses artigos, procura-se expressar e caracterizar o conjunto das forças sociais que moldam o campo educativo e o estado atual das disputas entre essas forças, configurado em alguns traços da face visível do nosso sistema de educação, aqui analisados.

A leitura desses textos suscita questões importantes e para as quais ainda não se delinearam respostas adequadas. No entanto, o que caracteriza uma boa sociologia é sua capacidade de colocar perguntas corretas, pois, a partir delas, podem ser estabelecidas boas explicações. Essa introdução tenta fazer uma exploração, ainda um tanto rústica, do manancial de possibilidades e caminhos de pesquisa que podem surgir a partir dos conhecimentos que vêm se acumulando. Aumentar essa lista é uma tarefa que cabe ao (à) leitor (a).

Maria Ligia de Oliveira Barbosa - Doutora em Sociologia pela UNICAMP. Professora do Programa de PósGraduação em Sociologia e Antropologia (PPGSA/ IFCS) da UFRJ. Autora do livro Os mecanismos de discriminação racial nas escolas brasileiras, em colaboração com Kaizô Beltrão, Sergei Soares e Maria Eugênia Ferrão. Publicou, entre outros artigos: "Au pays de la "culture anti-évaluation": les connaissances des élèves brésiliens. Revue Internationale d'Éducation, Sèvres. v. 43, p. 57 66, 2006. "Desigualdades sociais e a formação de expectativas familiares e de professores sobre o desempenho escolar de alunos do ensino fundamental". Cadernos do CRH. v. 17, p. 289-309, 2004, em colaboração com Laura Randall e "As profissões no Brasil e sua sociologia". Dados - Revista de Ciências Sociais. v. 46, p. 593-607, 2003. Áreas de Pesquisa: Desigualdades sociais, Sociologia da educação, Sociologia das profissões. 